\section{Use of immunodot blot and multiplex reverse transcriptase-polymerase chain reaction in dengue virus detection in macerates of Aedes aegypti larvae}

\author{
Aline T.A. Chagas, ${ }^{1}$ Michelle D. Oliveira, \\ Jose M.S. Mezencio, ${ }^{1}$ \\ Eduardo A.M. Silva, ${ }^{1}$ \\ Leandro L. Oliveira, ${ }^{1}$ Eduardo Honda, ${ }^{2}$ \\ Cynthia C. da Silva, ${ }^{1}$ Sérgio O. De Paula ${ }^{1}$ \\ ${ }^{1}$ Laboratory of Molecular \\ Immunovirology, Federal University of \\ Viçosa, ${ }^{2}$ Center of Medicine in Tropical \\ Medicine (CEPEM), Rondônia, Brazil
}

\begin{abstract}
The Dengue virus is the main arbovirus that affects man in terms of morbidity and mortality. The detection of the virus is very important for epidemiological surveillance, so here we propose to standardize and compare the immunodot blot (IDB) and multiplex reverse transcriptase-polymerase chain reaction (MRT-PCR) techniques to detect and characterize the dengue virus (DENV) serotypes in samples of Aedes aegypti larvae. Thus, the IDB and MRT-PCR techniques were standardized using macerated samples of larvae collected in nature. The use of monoclonal antibodies in IDB has not shown great results, but DENV detection through this method was possible using polyclonal antibodies. The distinction of serotypes 1, 2 and 3 was carried out by M-RTPCR.
\end{abstract}

\section{Introduction}

Dengue is an arbovirosis that has become a growing public health problem, especially in tropical and subtropical regions, where the disease is endemic. ${ }^{1}$ The Dengue virus (DENV) belongs to the Flaviviridae family, Flavivirus genus, it is an enveloped virus and has a single strand RNA of approximately $11 \mathrm{~kb}$ in size, which encodes 3 structural and 7 non-structural proteins. ${ }^{2}$

According to the World Health Organization, 2.5 billion people are estimated to live in at risk areas and there may be 50 million dengue infections worldwide every year. ${ }^{3}$ Until the ninth week of 2010, 227,109 cases of dengue were registered in Brazil, 222 cases of the hemorrhagic form and 65 deaths, with a circulation of serotypes 1,2 and 3 . The failure in the vector eradication, the re-infestation of the vector and the circulation of more than one serotype contribute to the dengue occurrence, favoring a substantial increase of hemorrhagic dengue cases. ${ }^{4}$

The DENV infection induces long term immunity for homologous serotypes, but confers only partial immunity against subsequent infection from the other three serotypes. ${ }^{5}$ This is highly related to the development of more severe forms of the disease and demonstrates the need to characterize the serotypes that are present in the locations where dengue is endemic. ${ }^{1,6}$

Efforts to reduce and control the vectors Aedes aegypti and Aedes albopictus females have been done primarily in campaigns to control the adult mosquito. For vector control, a system of active epidemiological surveillance is recommended. ${ }^{3}$ The DENV detection and distinction of serotypes in larvae and mosquitoes helps epidemiological surveillance because such information allows the detection of the serotype circulating within an area, which is crucial information for the surveillance of dengue epidemics, facilitating the implementation of preventative measures and the development of vector control strategies. ${ }^{7,8}$

The Enzyme Linked Immunosorbent-Assay (ELISA) technique has been a rapid and sensitive alternative to monitor arboviruses in wild populations of insects, in addition to providing a potential tool for rapid analysis of a large number of samples. The multiplex reverse transcriptase-polymerase chain reaction (RTPCR) technique is very sensitive to the viral RNA detection; however, although it is an extremely sensitive and specific technique it is not commonly used in routine laboratories because it is costly. ${ }^{8}$

The use of a technique that allows the DENV detection in local laboratories would facilitate the implementation of a more effective epidemiological surveillance. Thus, the immunodot blot (IDB) technique (or dot-ELISA) would be satisfactory, because it is also an inexpensive and effective technique.

The aim of this study is to standardize and use the IDB and multiplex reverse transcriptase-polymerase chain reaction (M-RT-PCR) techniques for DENV 1, 2 and 3 detection in macerates of $A$. aegypt $i$ larvae using monoclonal and polyclonal antibodies, evaluating the applicability of these methods in routine diagnostic laboratories to provide subsidies to health professionals allowing them to act quickly and effectively in areas where the disease is endemic.
Correspondence: Sérgio Oliveira De Paula, Laboratory of Molecular Immunovirology, Federal University of Viçosa, Av. PH Rolfs, s/n., Viçosa, 36571-000, Minas Gerais, CEP 36570-000, Brazil. Tel. +55.31.3899-2589/+55.31.3899-2559

Fax: $+55.31 .3899-2549$

E-mail: depaula@ufv.br

Key words: immunodot blot; multiplex reverse transcriptase-polymerase chain reaction; dengue control.

Acknowledgements: this work was supported by Conselho Nacional de Desenvolvimento Científico e Tecnológico (CNPq), Brazil (Grants \# 471221/2008-2 and INCT-Dengue \# 573876/20088). ATAC was supported by a CNPq scholarship and MDO was supported by a CAPES scholarship. Thanks to Jeffrey Ryan Oar from Oregon State University, USA for the English text revision.

Contributions: ATAC, MD0, design, field work, data collection, analysis, writing and editing of the manuscript; JMSM, data analysis, field work; EAMS, LLO, EH, CCS, design, field work, data collection and analysis; SOP, project leader, general coordination, financial management, and editing of the manuscript.

Received for publication: 13 October 2011. Revision received: 19 February 2012.

Accepted for publication: 17 March 2012.

This work is licensed under a Creative Commons Attribution NonCommercial 3.0 License (CC BYNC 3.0).

CC Copyright Chagas et al., 2012

Licensee PAGEPress, Italy

Microbiology Research 2012; 3:e13

doi:10.4081/mr.2012.e13

\section{Materials and Methods}

\section{Virus Strain}

DENV-1, Nauru Island strain and DENV-2, New Guinea C strain and DENV-3, H87 were kindly provided by Dr. Benedito A.L. de Fonseca (University of São Paulo, SP, Brazil) and were used as the positive control in this study. The viruses were replicated in C6/36 cells grown at $28{ }^{\circ} \mathrm{C}$ in a Leibovitz L- 15 medium containing $10 \%$ heat-inactivated fetal bovine serum, $10 \%$ tryptone phosphate broth, $150 \mathrm{U} / \mathrm{ml}$ streptomycin, and detected by IFA. ${ }^{9}$

\section{Larvae samples and antibodies}

The samples of $A$. aegypti larvae were provided by the Brazilian National Foundation of Health (FUNASA). The samples used were collected during the period of 2006 to 2007 in the following cities: Viçosa, Ponte Nova, Teixeiras, Urucânia, Jequeri, Caratinga, 
Entre Folhas and Ubaporanga, all located in the State of Minas Gerais. These samples were chosen randomly and had no information available about possible DENV infection. The cities analyzed belong to endemic regions and the larvae were collected in the summer, period of high incidence of dengue 2 in this region.

The monoclonal antibodies against the $\mathrm{E}$ protein of the dengue- $1,-2$ and -3 virus used in this study were isolated from the ascitic fluid of mice and were donated by the Aggeu Magalhães Institute - Recife - PE - Brazil. Human serum derived from convalescent patients who had dengue was used as a source of polyclonal antibodies. These dengue positive human serums were confirmed by MAC-ELISA. Peroxidase-conjugated goat anti-mouse IgG (Sigma, St. Louis, MO, USA) and peroxidase-conjugated rabbit anti-human IgG (Sigma, St. Louis, MO, USA) were used as conjugated antibodies in IDB.

\section{Antigen preparation}

A total of 120 samples of $A$. aegypti larvae were individually macerated with $50 \mu \mathrm{L}$ of PBST buffer $\mathrm{pH} 7.4,0.1 \mathrm{M}$ at $0^{\circ} \mathrm{C}$ in a microcentrifuge tube using a bat glass. The mixture was centrifuged at $12,000 \mathrm{~g}$ for $10 \mathrm{~min}$ utes and the supernatant was collected and divided into two aliquots: one to be examined by IDB and the other by M-RT-PCR.

\section{Immunodot blot}

Disks of nitrocellulose paper with a 0.45 $\mu \mathrm{m}$ pore size (Millipore, Billerica, MA,USA) were used as the solid support and were placed into 96 -well polystyrene microplates. The membranes were spotted with approximately $0.7 \mu \mathrm{L}$ per well of blocking solution (powdered milk 2\% in a PBST buffer) was added and the mixture was incubated for 20 minutes. A washing step was performed by adding $180 \mu \mathrm{L}$ of PBST buffer per well (wash solution) before the addition of $80 \mu \mathrm{L}$ per well of a primary antibody (monoclonal antibody anti-dengue 1 and 2 (1:3,000) and dengue positive polyclonal antibodies (1:10), followed by incubation for 60 minutes under constant agitation at $180 \mathrm{rpm}$. Later, a new washing step was performed and $80 \mu \mathrm{L}$ per well of peroxidase-conjugated goat antimouse IgG $(1: 1,000)$ was added. The mixture was incubated for 60 minutes under constant agitation and later was newly washed.

Finally $80 \mu \mathrm{L}$ per well of substrate solution was added, consisting of: $0.1 \%(\mathrm{w} / \mathrm{v})$ of 3.3 diaminobenzidine (Merck, Rahway, NJ, USA), $50 \mathrm{mM}$ Tris-HCl, pH 7.6, 1\% nickel chloride and hydrogen peroxide $0.1 \%$ (v/v). It was incubated under constant agitation for 15 minutes and the reaction was stopped by the addition of $100 \mu \mathrm{L}$ of deionized water. The positive results were evaluated visually by the presence of a brown dot. As positive controls was used concentrated DENV-1, -2 and -3 derived from cell cultures and PBSTween buffer was used as negative control to evaluate backgrounds effects.

\section{Multiplex reverse transcriptase- polymerase chain reaction}

The samples used in the standardization of IDB were also submitted for analysis by RTPCR in order to compare the compatibility of the results of the techniques used. Those samples submitted to RNA extraction were conduced by the TRIzol ${ }^{\circledR}$ LS method (GIBCO $\mathrm{BRL}^{\circledR}$, Grand Island, NY, USA) performed as described by De Paula et al. ${ }^{10}$

The cDNA was made in a microcentrifuge tube where $2 \mu \mathrm{g}$ of the extracted RNA, $0.1 \mathrm{mM}$ of dNTP (Amersham-Pharmacia, Freiburg, Germany) and 25 pmol of a $\mathrm{p}(\mathrm{dN}) 6$ primer (sequence CGTA) was added. This mixture was heated at $65{ }^{\circ} \mathrm{C}$ for 5 minutes, quickly placed on ice for 2 minutes, and subsequently centrifuged at $8,000 \mathrm{~g}$ for 1 minute. $4 \mu \mathrm{L}$ of a $5 \mathrm{x}$ reaction buffer (Invitrogen, Carlsbad, CA, USA), $2 \mu \mathrm{L}$ DTT (Invitrogen , Carlsbad, CA, USA) and $1 \mu \mathrm{L}$ of deionazed water was added. The samples were incubated at $37^{\circ} \mathrm{C}$ for 2 minutes and then centrifuged at 13,000 $\mathrm{g}$ for 1 minute. Finally, $1 \mu \mathrm{L}(200 \mathrm{u})$ of M-MLVRT (Invitrogen, Carlsbad, CA, USA) was added and the system was incubated at $25^{\circ} \mathrm{C}$ for 10 minutes, followed by $37^{\circ} \mathrm{C}$ for $50 \mathrm{~min}$ utes and then $70^{\circ} \mathrm{C}$ for 15 minutes.

M-PCR was performed using approximately $220 \mathrm{ng}$ of cDNA, $2.5 \mu \mathrm{L}$ of buffer $10 \mathrm{x}$ (Fermentas, Burlington, Canada), $0.1 \mathrm{mM}$ of dNTPs (Amersham-Pharmacia, Freiburg, Germany), 1U of Taq DNA polymerase (Fermentas, Burlington, Canada), $1.5 \mu \mathrm{L}$ $\mathrm{MgCl}_{2}$ and 50 pmol of each primer and the volume was completed up to $25 \mu \mathrm{L}$ with milliQ water. RT-PCR was conducted according to the following protocol: $94^{\circ} \mathrm{C}$ for $5 \mathrm{~min}$ utes (Hot Start PCR) followed by 40 cycles of $94^{\circ} \mathrm{C}$ for 1 minute, $55^{\circ} \mathrm{C}$ for 1 minute and $72^{\circ} \mathrm{C}$ for 1 minute. The final extension was made at $72^{\circ} \mathrm{C}$ for 10 minutes. The amplicons were detected in polyacrilamide gel $12 \%$ stained with silver nitrate. The primers sequences are: D1: 5' TCAATATGCTGAAACGCGCGAGAAACCG 3', TS1: 5' CGTCTCAGTGATCCGGGGG 3', TS2: 5' CGCCACAAGGGCCATGAACAG 3', TS3: 5' TAACATCATCATGAGACAGAGC 3' and DEN4: 5' TGTTGTCTTAAACAAGAGAGGTC 3'. The expected sizes of the amplification products are: 482 bp (dengue1), 119 bp (dengue-2), 290 bp (dengue-3), and 389 bp (dengue-4). ${ }^{11,12}$

[Microbiology Research 2012; 3:e13]

\section{Results}

\section{Evaluation of the monoclonal and polyclonal antibodies in immun- odot blot}

The use of monoclonal antibodies as a primary antibody in IDB allowed the distinction of serotypes 1 and 2 only when the concentrated viral samples were used as antigens (Figure 1). The use of polyclonal antibodies, derived from the serum of human patients that confirmedly had dengue, proved to be effective in detecting DENV in macerated samples of larvae (Figure 2). Out of the 120 samples analyzed by IDB, 29 showed positive results.

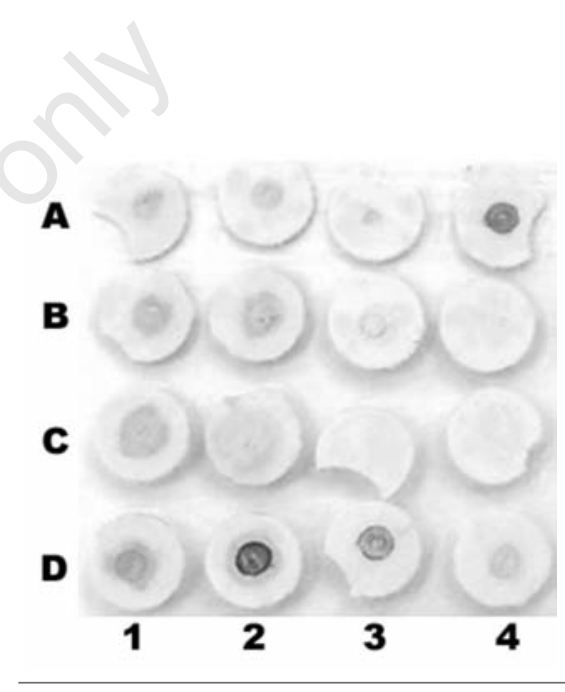

Figure 1. Evaluation of the use of monoclonal antibodies in immunodot blot technique. A) dengue virus (DENV)-1 + Monoclonal $\mathrm{Ab}$ antidengue 1; $\mathrm{B}) \mathrm{DENV}-1$ + Monoclonal Ab antidengue 2; C) DENV$2+$ Monoclonal $\mathrm{Ab}$ antidengue $1 ; \mathrm{D}$ ) DENV-2 + Monoclonal Ab antidengue 2. The numbers refers to the monoclonal $\mathrm{Ab}$ dilutions: $1(500 x), 2(1,000 x), 3(2,000 x)$, $4(3,000 x)$.

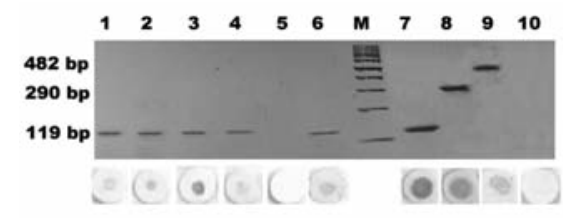

Figure 2. Samples of $A$. aegypti larvae submitted to Multiplex reverse transcriptasepolymerase chain reaction and immunodot blot. 1 to 6: samples of larvae, M: 100-bp ladder, 7: positive dengue virus (DENV)-2 control, 8: positive DENV-3 control, 9: positive DENV-1 control; 10: dengue negative larvae control. 
Table 1. Number of samples analyzed in each city showing the number of positive samples to immunodot blot and/or multiplex reverse transcriptase-polymerase chain reaction.

\begin{tabular}{lcccc} 
City & Number of samples & $\begin{array}{c}\text { Positive samples } \\
\text { (IDB alone) }\end{array}$ & $\begin{array}{c}\text { Positive samples } \\
\text { (both IDB and M-RT-PCR) }\end{array}$ & $\begin{array}{c}\text { Positive samples } \\
\text { (M-RT-PCR alone) }\end{array}$ \\
Viçosa & 31 & 0 & $17(54.8 \%)$ & $2(6.5 \%)$ \\
Ponte Nova & 23 & 0 & $2(8.7 \%)$ & $1(4.3 \%)$ \\
\hline Teixeiras & 13 & 0 & $2(15.4 \%)$ & $1(7.7 \%)$ \\
Urucânia & 12 & 0 & $1(8.3 \%)$ & $1(8.3 \%)$ \\
\hline Jequeri & 15 & 0 & $4(26.7 \%)$ & $1(6.7 \%)$ \\
Ubaporanga & 12 & 0 & 0 & $2(16.7 \%)$ \\
\hline Entre Folhas & 14 & 0 & $3(21.4 \%)$ & 0 \\
TOTAL & 120 & $0(0 \%)$ & $29(24.2 \%)$ & $8(6.7 \%)$
\end{tabular}

IDB, immunodot blot; M-RT-PCR, multiplex reverse transcriptase-polymerase chain reaction.

\section{Multiplex reverse transcriptase- polymerase chain reaction}

Out of the 120 analyzed samples, 37 were dengue positive by M-RT-PCR. Of the 91 samples that showed negative results by IDB, 8 were confirmed by M-RT-PCR, and the other samples analyzed by this technique showed negative results (Table 1). All positive results obtained by IDB were confirmed by M-RT-PCR and were positive for the serotype DENV-2. Some of these results are illustrated in Figure 2.

\section{Discussion}

The detection of DENV is fairly well described in clinical samples and there are several technical standards for this purpose, such as immunoassays, virus isolation, virus neutralization, hemagglutination inhibition and molecular techniques. ${ }^{13-15}$ There are also protocols described using IDB for the detection of antidengue antibodies in clinical samples compared with other techniques, such as hemagglutination inhibition for clinical diagnosis. In such studies IDB has demonstrated to have equal or superior sensitivity. The sensitivity of the technique has been compared in other situations to the conventional ELISA technique, showing to be more sensitive. ${ }^{16,17}$ Moreover, it is a less expensive that can be applied in laboratories with few resourses and in the field. Given the reality of the laboratory surveillance of different areas where dengue is endemic, this technique proves to be a viable alternative in such regions.

The distinction of serotypes both in clinical samples of larvae and mosquitoes is most commonly described using RT-PCR and its variables, for example, Real-time PCR and Nested PC. . $^{13,18-20}$

Similar studies employing RT-PCR to detect the circulating DENV serotypes in specific localities are available in literature present- ing great results. ${ }^{7,21}$

IDB has been satisfactorily standardized for DENV detection in A. aegypti macerates of larvae and mosquitoes using polyclonal antibodies. The viral detection using monoclonal antibodies was not possible probably due to the fact that monoclonal antibodies recognize only one antigenic determinant and the source of viral particles used in the tests that were performed show probably due to the fact that monoclonal antibodies recognize only one determinant and the source of viral particles used in this study show low viral titer. On the other hand, the polyclonal antibodies derived from the serum of convalescent patients show high antibody levels and contain antibodies that recognize a large variety of antigens, permitting the detection of smaller amounts of antigens. One disadvantage of the use of polyclonal antibodies in IDB is the inability to distinguish the viral serotype.

M-RT-PCR allowed the detection of the viral presence and characterization of viral serotypes. In the samples analyzed, the predominance of the serotype DENV-2 was observed. Furthermore, most of the cities analysed showed positive results, indicating a risk of the occurrence of dengue cases. The samples that had negative results by IDB and positive results by M-RT-PCR show that the MRT-PCR technique is more sensitive in DENV detection. The sensitivity of the IDB in this study was 78\% compared with M-RT-PCR. This high percentage for samples obtained from nature can be explained because the cities analyzed belong to endemic regions and the larvae were collected in the summer, a high incidence period of dengue in Brazil.

A similar study conducted by Ludolfs et al ${ }^{22}$ proposed the use of IDB and RT-PCR techniques for the detection of antidengue antibodies in patients in the convalescent period using serotype-specific recombinant antigens. Despite it being possible to detect the antidengue antibodies using monoclonal antibod- ies, there was a high rate of cross reactions and the exact definition of serotypes was only possible by RT-PCR.

$\mathrm{Xu}$ et al..$^{23}$ describes the development of an antigen capture immunoassay for DENV detection in clinical samples using monoclonal antibodies. Despite the absence of cross reactions between dengue serotypes and other flaviviruses being reported, the technique was standardized in order to detect only the presence of serotype DEN-1.

Despite the use of larvae having the disadvantage of variable frequencies of vertical transmission and not representing current activity, the use of larvae can represent a good source of information because DENV can be isolated from them and the early detection of DENV in larvae that could become infective adults in the future would be desirable in a prevention program. The standardization of such techniques to be used in larvae is also advantageous because larvae are easier to collect by health agents, which already collect larvae to identify the presence of the vector in Brazilian cities. Storing such samples for a long time at room temperature, which increases the number of samples available for a surveillance program (that are often captured using traps), does not interfere with the quality of the results. ${ }^{24}$ Since the number of larvae collected can be quite large, the possibility of pooling samples to make large-scale testing could be a feasible alternative.

The importance of continual epidemiologic studies and use of classic and molecular approaches in the surveillance of dengue becomes more important with the discovery of serotype DENV-4 circulating in Brazil co-circulating with other serotypes, which represents an increased risk of developing the hemorrhagic form in people that have already been sensitized by previous dengue infections but are not protected against infection with DENV4. ${ }^{25}$ These results allow us to propose the use of IDB and M-RT-PCR as a tool for epidemio- 
logical surveillance of dengue. Results generated from this type of analysis would be useful for public health politics, which could intervene more effectively in combating dengue, from monitoring vectors, developing policies for the prevention of the disease and even assisting in the definition of the hemorrhagic form diagnosis.

\section{Conclusions}

The techniques proposed in this study, when used together, can detect and distinguish the presence of the dengue virus in A. aegypti larvae samples. Although IDB have shown less sensitive than the other technique in study, it is proposed to conduct an initial survey by IDB and, from the positive samples, identify the serotype circulating in each region by M-RTPCR. This first analysis by IDB can be conducted in local laboratories, facilitating the establishment of a more effective surveillance, since the technique M-RT-PCR is costly.

\section{References}

1. Halstead SB. Dengue. Lancet 2007;370: 1644-52.

2. Guzman MG, Halstead SB, Artsob H, et al. Dengue: a continuing global threat. Nat Rev Microbiol 2010;8:7-16.

3. World Health Organization. Dengue and dengue haemorrhagic fever. 2008. Available from: http://www.who.int/mediacentre/factsheets/fs117/en (Accessed on 30 May 2008).

4. Pan-Health Organization: Update of data of dengue in Brazil, 2010. Available from: http://new.paho.org/bra/index.php?option= com_content\&task=view\&id=1104\&Itemi $\mathrm{d}=463$, (Accessed on 26 November 2010).

5. Wahala WMPB, Kraus AA, Haymore LB, et al. Dengue virus neutralization by human immune sera: role of envelope protein domain III - reactive antibody. Virology
2009;392:103-13.

6. Nielsen DG. The relationship of interacting immunological components in dengue pathogenesis. Virol J 2009;6:211.

7. Pinheiro CSV, Tadei WP, Barros PMSS, et al. Detection of dengue virus serotype 3 by reverse transcriptionpolymerase chain reaction in Aedes aegypti (Diptera, Culicidae) captured in Manaus, Amazonas. Mem Inst Oswaldo Cruz 2005; 100:833-9.

8. Samuel PP, Tyagi BK. Diagnostic methods for detection \& isolation of dengue viruses from vector mosquitoes. Ind $\mathrm{J}$ Med Res 2006;123:615-28.

9. Tesh RB. A method for the isolation and identification of dengue viruses, using mosquito cell cultures. Am J Trop Med Hyg 1979;28:1053-9.

10. De Paula SO, Nunes C, Matos R, et al. Comparison of techniques for extracting viral RNA from isolation-negative serum for dengue diagnosis by the polymerase chain reaction. J Virol Methods 2001;98: 119-25.

11. Harris E, Roberts R, Smith L, et al. Typing of dengue viruses in clinical specimens and mosquitoes by Single-Tube Multiplex Reverse Transcriptase PCR. J Clin Microbiol 1998;36:2634-9.

12. Lanciotti RS, Calisher $\mathrm{CH}$, Gubler DJ, et al. Rapid detection and typing of dengue viruses from clinical samples by using reverse transcriptase-polymerase chain reaction. J Clin Microbiol 1992;30:545-51.

13. De Paula SO, Lima DM, Fonseca BAL. Detection and identification of dengue-1 virus in clinical samples by a nested-PCR followed by restriction enzyme digestion of amplicons. J Med Virol 2002;66:529-34.

14. Dussart P, Labeau B, Lagathu G, et al. Evaluation of an enzyme immunoassay for detection of dengue virus NS1 antigen in human serum. Clin Vaccine Immunol 2006;13:1185-9.

15. Poersch CEO, Pavonia DP, Queiroz MH, et al. Dengue virus infections: comparison of methods for diagnosing the acute disease. J Clin Virol 2005;32:272-7.

16. Abhyankar AV, Dash PK, Saxena P, et al.
Comparison of a dipstick dot-ELISA with commercial assays for anti-dengue virus IgM antibodies. Viral Immunol 2006;19: 630-6.

17. Cardosa MJ, Hooi TP, Shaari NS. Development of a dot enzyme immunoassay for dengue 3: A sensitive method for the detection of antidengue antibodies. J Virol Methods 1988;22:81-8.

18. Gomes ALV, Silva AM, Cordeiro MT, et al. Single-tube nested PCR using immobilized internal primers for the identification of dengue virus serotypes. J Virol Methods 2007;145:76-9.

19. Kong YY, Thay CH, Tin TC, Devi S. Rapid detection, serotyping and quantitation of dengue viruses by TaqMan real-time onestep RT-PCR. J Virol Methods 2006;138: 123-30.

20. Urdaneta L, Herrera F, Pernalete M, et al. Detection of dengue viruses in fieldcaught Aedes aegypti (Diptera: Culicidae) in Maracay, Aragua State, Venezuela by type-specific polymerase chain reaction. Infect Genet Evol 2005;5:177-84.

21. Kow CY, Koon LL, Yin PF. Detection of dengue viruses in field caught male aedes aegypti and Aedes albopictus (Diptera: Culicidae) in Singapore by type-specific PCR. J Med Entomol 2001;38:475-9.

22. Ludolfs D, Schilling S, Altenschmidt J, Schmitz H. Serological differentiation of infections with dengue virus serotypes 1 to 4 by using recombinant antigens. J Clin Microbiol 2002;40:4317-20.

23. Xu H, Di B, Pan Y, et al. Serotype 1-specific monoclonal antibody-based antigen capture immunoassay for detection of circulating nonstructural protein NS1: Implications for early diagnosis and serotyping of dengue virus infections. $\mathrm{J}$ Clin Microbiol 2006;44:2872-8.

24. Thenmozhi V, Kabilan L, Samuel PP, Dash AP. Detection of dengue virus antigens in desiccated mosquitoes: an improved tool for surveillance. Trop Med Int Health 2005;10:187-9.

25. Figueireda RMP, Naveca FG, Bastos MS, Farias IP. Dengue virus type 4, Manaus, Brazil. Emerg Infect Dis 2008;14:667-9. 